\title{
Is greater generic competition also linked to lower drug prices in South Korea?
}

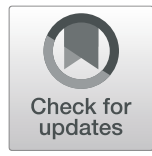

Kyung-Bok SoniD

\begin{abstract}
Background: Although the association between the price of generic drugs and market competitiveness has been explored in various high-income countries, this association has not been empirically evaluated in South Korea. We aim to determine the association between the prices of generic drugs and market competitiveness in South Korea.

Methods: A list of originator drugs approved by the national authority from 2000 to 2019 and their corresponding generic drugs were grouped along with the baseline information. The market was categorized into four groups based on the number of manufacturers: duopoly (2 manufacturers); low- (3-25 manufacturers); medium- (26-75 manufacturers); and high-competition (more than 76 manufacturers) markets. Price variance, calculated as the difference between the maximum price and minimum price divided by the maximum price, was obtained. A multivariate regression model was applied to regress price variance on the characteristics of market competitiveness, controlling for the characteristics of the originator drugs and their price level in the market.

Results: A total of 986 originator drugs were identified and then divided into duopoly (31\%), low- (56\%), medium(9\%), and high-competition (4\%) markets; the median of the price variance for these markets was $0.013,0.077,0.200$, and 0.228 , respectively. In a multivariate regression model, price variance was associated with the characteristics of the originator drug, including the Anatomical Therapeutic Chemical classification, the route of administration, and the approval year. Controlling for the characteristics of the originator drugs, market competitiveness was positively associated with price variance.
\end{abstract}

Conclusions: The positive association between price variance and market competitiveness is still consistent in South Korea, where rare price competition among a large number of generic manufacturers has been reported. However, no significant price variance was observed between medium- and high-competition markets. These findings support policies for managing a large number of generic manufacturers in South Korea.

Keywords: Generics, Competition, Drug price, Market, South Korea

\section{Background}

When a pharmaceutical patent or statutory exclusivity expires, manufacturers can be granted marketing authorization for generic substitutes and penetrate originator markets [1-4]. In principle, generic drugs contain exactly the same active ingredient as the originator drugs, and generic drugs are certified by authorities to

\footnotetext{
Correspondence: sonkyungbok@gmail.com

College of Pharmacy, Ewha Womans University, 52Ewhayeodae-gil, Seodaemun-gu, Seoul 03760, South Korea
}

be perfect substitutes for the originator [5-8]. Thus, the entry of a perfect substitute, or a generic drug, will trigger price competition, bringing to an end the monopoly rent enjoyed by the originator manufacturer [9-13].

Price competition in pharmaceuticals, particularly for prescription drugs, matters in high-income countries [14-17]. Prescription drug expenditures in the United States have increased at a pace far beyond that in other sectors of the health system [18-20]. More specifically, manufacturers of originator drugs set prices as high as the market will bear during the limited period of patent

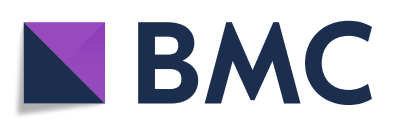

(c) The Author(s). 2020 Open Access This article is licensed under a Creative Commons Attribution 4.0 International License, which permits use, sharing, adaptation, distribution and reproduction in any medium or format, as long as you give appropriate credit to the original author(s) and the source, provide a link to the Creative Commons licence, and indicate if changes were made. The images or other third party material in this article are included in the article's Creative Commons licence, unless indicated otherwise in a credit line to the material. If material is not included in the article's Creative Commons licence and your intended use is not permitted by statutory regulation or exceeds the permitted use, you will need to obtain permission directly from the copyright holder. To view a copy of this licence, visit http://creativecommons.org/licenses/by/4.0/ The Creative Commons Public Domain Dedication waiver (http://creativecommons.org/publicdomain/zero/1.0/) applies to the data made available in this article, unless otherwise stated in a credit line to the data. 
or statutory exclusivity. To address these issues, governments have established several ways to negotiate lower prices for originator drugs and to expand the use of health technology assessment for reimbursement decisions [21-23]. Furthermore, governments are assessing how they can lower pharmaceutical expenditures through generics [14, 24].

Generic drugs can be used for discounted price compared to the originate drug. The role of generic drugs or the number of generic manufacturers in reducing drug prices has been well documented in the previous literature $[11,12]$. The price of generics with 2 or fewer manufacturers is more likely to be increased compared to that of generics with 3 or more manufacturers. Sometimes, price hikes occur for generic drugs in markets where an insufficient number of generic manufacturers exist. The price of pyrimethamine, albendazole, and praziquantel increased by $5433 \%, 1920$, and $356 \%$, respectively $[15,25,26]$. These cases demonstrate that the number of generic manufacturers and the introduction of generics are critical in managing drug prices and pharmaceutical expenditures.

Although the association between the price of generic drugs and market competitiveness has been explored in various high-income countries, this association has not been empirically evaluated in South Korea. The pharmaceutical market in South Korea is characterized by a large number of generic manufacturers, specifically 416 manufacturers, with rare price competition among generics [16, 27]. Thus, South Korea is an ideal case to test the association between the price of generics and market competitiveness. In the present study, we used a whole list of reimbursed medicines under the National Health Insurance Services (NHIS) to investigate the association between competition and lower drug prices in South Korea.

\section{Methods}

This study is interested in investigating the association between the price of generics and market competitiveness in South Korea. To this end, a list of originator drugs approved by the national authority from 2000 to 2019 and their corresponding generic drugs were grouped along with the baseline information. We compiled the originators and their corresponding generics as the subjects of the study, counted the number of available drugs, and retrieved their price under the NHIS. In this study, an originator is defined as a drug that was the first to be granted marketing authorization, while generics are defined as drugs that have the same active ingredient, strength, and route of administration as the originator and that were granted marketing authorization after the originator.

\section{Data sources}

The list of reimbursed medicines under the NHIS, provided by the Health Insurance Review and Assessment Services (HIRA), was retrieved. The list contains information on drugs such as the generic and proprietary name of the drug and its strength, route of administration, manufacturer, and reimbursed price. Information on all drugs approved by the Ministry of Food and Drug Safety (MFDS) from 2000 to 2019 was also extracted. In particular, the Korea Pharmaceutical Information Service (KPIS $)^{1}$ provides information on drugs such as the generic and proprietary name of the drug and its strength, route of administration, Anatomical Therapeutic Chemical (ATC) classification, type (including chemicals and biologics), date of marketing approval, and manufacturer. With the information on the generic name of the drug and its strength and route of administration, the list of originator drugs and their corresponding generics were grouped.

\section{Study design \\ Dependent variables}

We used price variance, calculated as the difference between the maximum price and minimum price divided by the maximum price in the originator-generic set, as the dependent variable to measure the price competition.

\section{Control variables}

We chose a set of variables, specifically the characteristics of the originator drug and its manufacturer, to control for their effects. First, we categorized the characteristics of the originator drug based on the drug's ATC classification, route of administration, year of marketing authorization, and type. Second, we grouped the manufacturers of the originator drugs into domestic and overseas manufacturers based on the origin of the manufacturers. In particular, the dataset provided by the Ministry of Trade, Industry and Energy was used to identify the origin of the manufacturers. ${ }^{2}$

\section{Independent variables}

The characteristics of the market were used to determine the association between the price of generics and market competitiveness. First, we counted the manufacturers of a certain drug, including both the originator and generics, and categorized the market into four groups based on the cumulative number of manufacturers: duopoly, low-, medium-, and high-competition markets. In a duopoly market, only two manufacturers

\footnotetext{
${ }^{1}$ Available at https://biz.kpis.or.kr/kpis_biz/index.jsp

${ }^{2}$ Available at http://www.motie.go.kr/motie/py/sa/companyGuide/ companyguide.jsp
} 
exist: one is the originator manufacture, and the other is the generic manufacturer. A low-competition market is defined as a market with more than two and less than 26 manufacturers, while a medium-competition market is defined as a market with more than 25 and less than 76 manufacturers. Similarly, a high-competition market is defined as a market with more than 75 manufacturers participating in the market. Second, we gathered information on the maximum price in the set to understand the characteristics of the drug in the market and categorized the maximum unit price into five levels. Level I indicates low-cost medicine that is under $1000 \mathrm{KRW}$ (approximately 0.86 USD), while Level V indicates highcost medicine, which is above 1 million KRW (approximately 864 USD). Finally, we retrieved information regarding the designation of new drug applications by the MFDS.

\section{Statistical analysis}

Descriptive analyses were used to present the differences between the four markets, including the duopoly, low-, medium-, and high-competition markets. In particular, the chi-squared test was applied for the categorical variables, and analysis of variance was conducted for the continuous variables to examine whether the variables of interest differed across the four markets.

A multivariate regression model was applied to examine the factors that affected the price variance, particularly for market competitiveness. The variables were the characteristics of the originator drug, manufacturers, and the market. In a simple model, the characteristics of the originator drug and manufacturers were included.
Then, we added the market variables (new drug designation, market competitiveness, and maximum reimbursed price) in the expanded model. We used heteroscedasticity-consistent standard errors for the analysis to obtain the correct standard error against heteroscedasticity. Data management and analysis were performed using $\mathrm{R}$ statistical software (version 3.4.3). Statistical significance is noted by $p$-values less than 0.05 .

$$
\begin{aligned}
\text { Price variance }_{\mathrm{i}}= & \beta_{0}+\beta_{1} \mathrm{ATC}_{\mathrm{i}}+\beta_{2} \text { Route }_{\mathrm{i}}+\beta_{3} \text { Year }_{\mathrm{i}} \\
& +\beta_{4} \text { Types }_{\mathrm{i}}+\beta_{5} \text { Manufacturer }_{\mathrm{i}}+\varepsilon_{\mathrm{i}} \\
\text { Price variance }_{\mathrm{i}}= & \beta_{0}+\beta_{1} \mathrm{ATC}_{\mathrm{i}}+\beta_{2} \text { Route }_{\mathrm{i}}+\beta_{3} \text { Year }_{\mathrm{i}} \\
& +\beta_{4} \text { Types }_{\mathrm{i}}+\beta_{5} \text { Manufacturer }_{\mathrm{i}} \\
& +\beta_{6} \text { Competitiveness }_{\mathrm{i}}+\beta_{7} \text { Price }_{\mathrm{i}} \\
& +\beta_{8} \text { NDA }_{\mathrm{i}}+\varepsilon_{\mathrm{i}}
\end{aligned}
$$

\section{Results}

\section{Subjects of the study}

During a 20-year period, a total of 986 sets of originator and corresponding generic drugs were identified. Note that a monopoly market, in which generic drugs are not available, was excluded from our model. Figure 1 presents the cumulative number of sets and the number of drugs in the set, indicating that one-third of sets are duopoly markets. Interestingly, 39 sets (4\%) include more than 75 generic manufacturers.

\section{Descriptive analysis}

Table 1 presents the descriptive statistics of the dependent and explanatory variables in our model. The

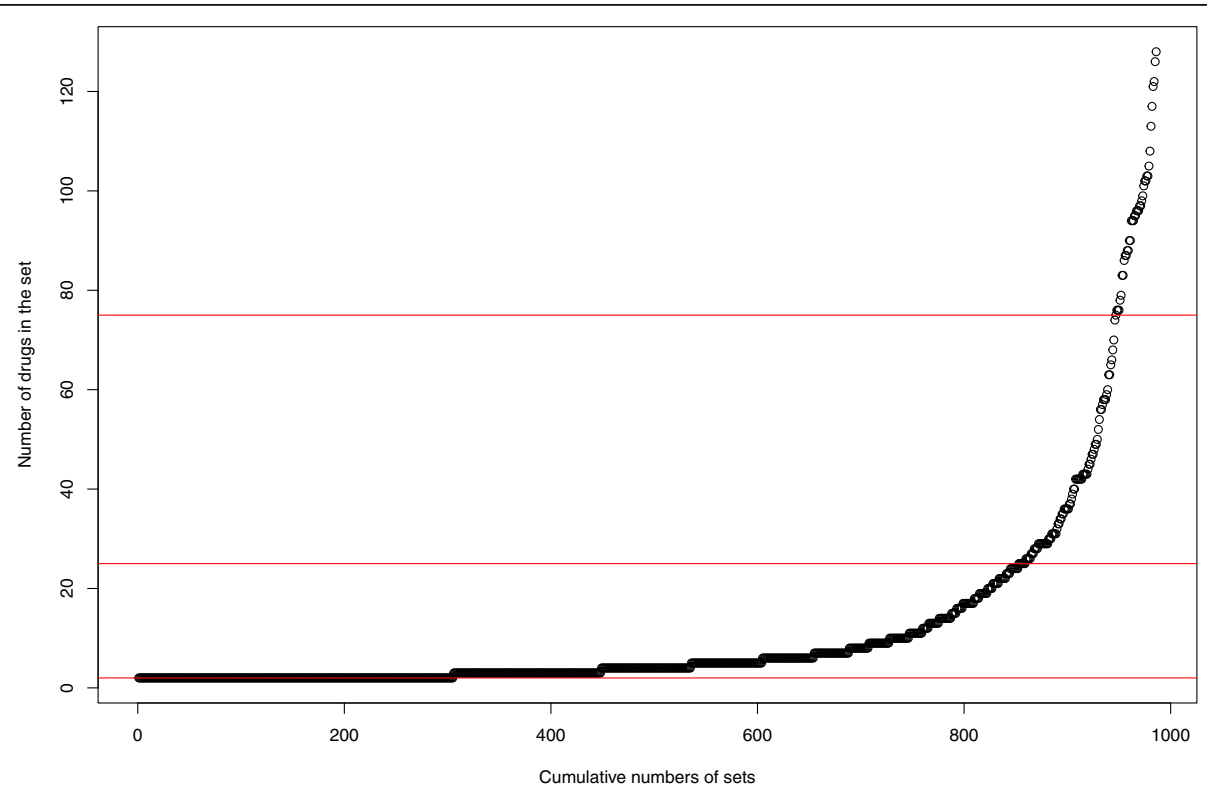

Fig. 1 The cumulative number of sets and the number of drugs in the set 
Table 1 Characteristics of the subjects in this study

\begin{tabular}{|c|c|c|c|c|c|c|}
\hline \multirow[t]{2}{*}{ Variables } & \multirow{2}{*}{$\begin{array}{l}\text { All } \\
N=986\end{array}$} & \multirow{2}{*}{$\begin{array}{l}\text { Duopoly } \\
\text { (2) } \\
305 \\
\end{array}$} & \multirow{2}{*}{$\begin{array}{l}\text { Low-competition } \\
\text { (3-25) } \\
554\end{array}$} & \multirow{2}{*}{$\begin{array}{l}\text { Medium- } \\
\text { Competition } \\
(26-75) \\
88\end{array}$} & \multirow{2}{*}{$\begin{array}{l}\text { High- } \\
\text { competition } \\
(76-) \\
39\end{array}$} & \multirow[t]{2}{*}{$p$-value } \\
\hline & & & & & & \\
\hline \multicolumn{7}{|l|}{ Price variance } \\
\hline Mean & 0.1167 & 0.0683 & 0.1160 & 0.2268 & 0.2566 & \multirow[t]{3}{*}{$<0.0001$} \\
\hline Median & 0.0714 & 0.0130 & 0.0774 & 0.2004 & 0.2286 & \\
\hline SD & 0.1416 & 0.1000 & 0.1366 & 0.1782 & 0.1693 & \\
\hline \multicolumn{7}{|l|}{ ATC } \\
\hline $1(\mathrm{~J} / \mathrm{L})$ & 168 & 58 & 97 & 11 & 2 & \multirow[t]{4}{*}{$<0.0001$} \\
\hline $2(A / B / C)$ & 302 & 100 & 140 & 41 & 21 & \\
\hline $3(\mathrm{M} / \mathrm{N})$ & 239 & 57 & 148 & 24 & 10 & \\
\hline 4 (Others) & 277 & 90 & 169 & 12 & 6 & \\
\hline \multicolumn{7}{|l|}{ Route } \\
\hline Oral & 635 & 156 & 354 & 86 & 39 & \multirow[t]{3}{*}{$<0.0001$} \\
\hline Injection & 206 & 103 & 101 & 2 & - & \\
\hline Others & 145 & 46 & 99 & - & - & \\
\hline \multicolumn{7}{|l|}{ Year } \\
\hline Mean & 2007 & 2008 & 2007 & 2006 & 2005 & \multirow[t]{3}{*}{0.0001} \\
\hline Median & 2006 & 2007 & 2006 & 2006 & 2005 & \\
\hline SD & 5.3662 & 5.2816 & 5.5529 & 4.5851 & 3.8231 & \\
\hline \multicolumn{7}{|l|}{ Types } \\
\hline Biologics & 50 & 28 & 9 & 9 & 4 & \multirow[t]{2}{*}{$<0.0001$} \\
\hline Chemicals & 936 & 277 & 545 & 79 & 35 & \\
\hline \multicolumn{7}{|c|}{ New drug application } \\
\hline Yes & 154 & 34 & 96 & 13 & 11 & \multirow[t]{2}{*}{0.0142} \\
\hline No & 832 & 271 & 458 & 75 & 28 & \\
\hline \multicolumn{7}{|l|}{ Manufacturers } \\
\hline Domestic & 623 & 187 & 372 & 49 & 15 & \multirow[t]{2}{*}{0.0008} \\
\hline Overseas & 363 & 118 & 182 & 39 & 24 & \\
\hline \multicolumn{7}{|l|}{ Price } \\
\hline $\mathrm{I}\left(<10^{3} \mathrm{KRW}\right)$ & 502 & 120 & 283 & 67 & 32 & \multirow[t]{5}{*}{$<0.0001$} \\
\hline$\|\left(10^{3} \leq<10^{4}\right)$ & 269 & 86 & 159 & 17 & 7 & \\
\hline III $\left(10^{4} \leq<10^{5}\right)$ & 154 & 67 & 83 & 4 & - & \\
\hline $\operatorname{IV}\left(10^{5} \leq<10^{6}\right)$ & 55 & 26 & 29 & - & - & \\
\hline$V\left(10^{6} \leq\right)$ & 6 & 6 & - & - & - & \\
\hline
\end{tabular}

subjects were categorized into four markets based on the cumulative number of manufacturers in the market. Approximately $31,56,9$, and $4 \%$ of the markets are duopoly, low-, medium-, and high-competition markets, respectively. The mean and median of price variance among all sets were 0.1167 and 0.0714 , respectively, indicating that generics are available in the market discounted by 11.67 and $7.14 \%$. When we separated the markets, increased trends were observed in the mean and median of price variance. The mean of price variance was $0.0683,0.1160,0.2268$, and 0.2566 for duopoly, low-, medium-, and high-competition markets, respectively. Similarly, the median of price variance for the same markets was 0.0130, 0.0774, 0.2004, and 0.2286 .

In a similar vein, Fig. 2 presents the cumulative number of sets and their price variance. The first graph in Fig. 2 shows the curve for the whole market, while the remaining graphs present the curve for the duopoly, low-, and medium- and high-competition markets. The 


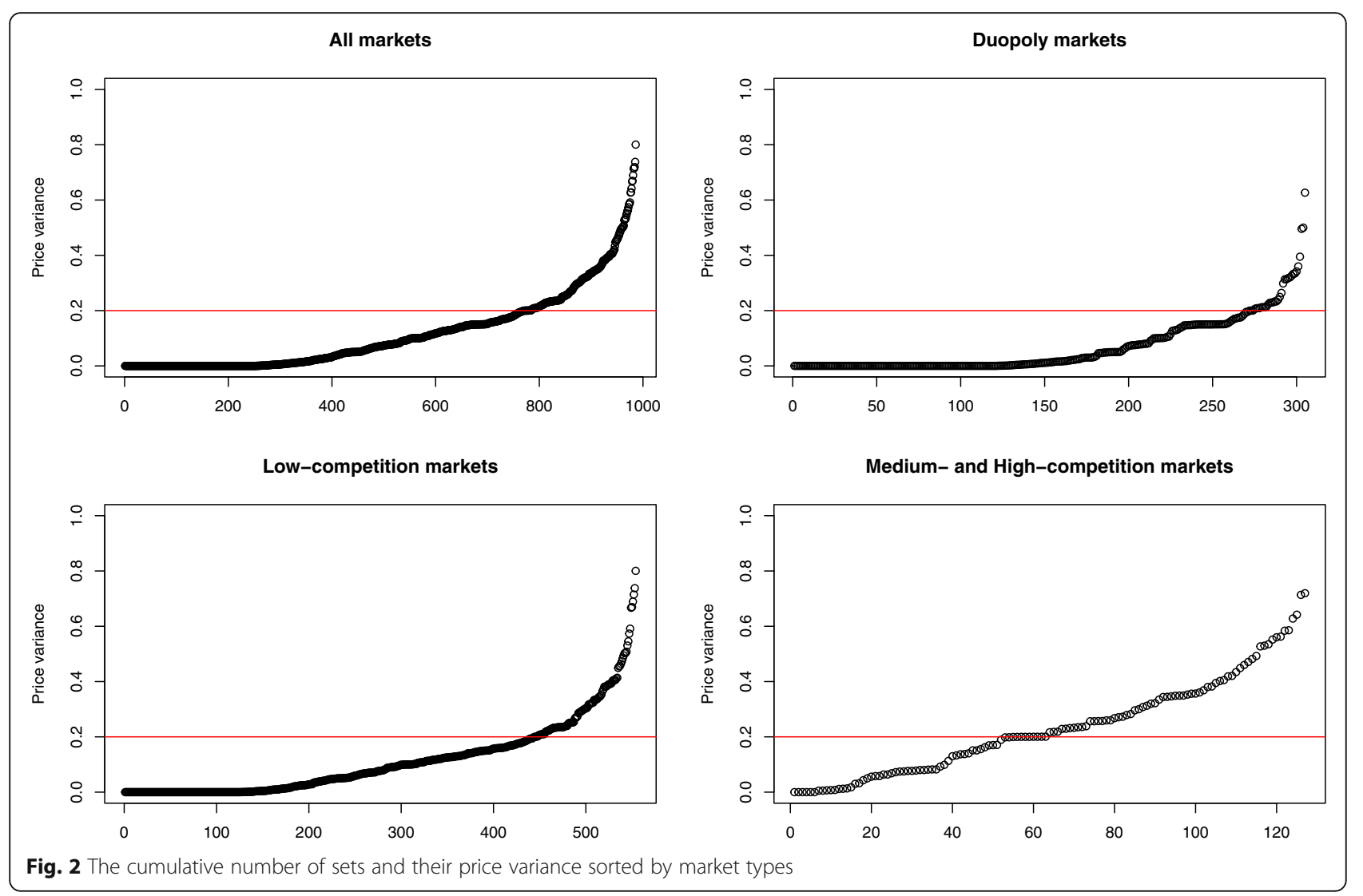

majority of sets in duopoly and low-competition markets present a small price variance, while a large number of sets in medium- and high-competitive markets present a large price variance. More specifically, 89, 80, 45, and $41 \%$ of sets in the duopoly, low-, medium-, and highcompetition markets, respectively, show a price variance less than 0.2. Interestingly, the difference between the duopoly and low-competition markets (89\% versus $80 \%$ ) and the difference between the medium- and highcompetition markets ( $45 \%$ versus $41 \%$ ) were marginal.

The characteristics of the originator drug, its manufacturer, and the market are also presented in Table 1. Significant differences were noted among the four markets. In particular, the ATC classification, route of administration, year of marketing authorization, type of originator, designation of new drug applications, characteristics of the manufacturer, and reimbursed price were different among four markets. Note that 39 out of 986 sets (4\%) include more than 75 generic drugs. The majority of sets in the high-competition market were chemical drugs (90\%), belonging to the alimentary tract and metabolism (A), blood and blood forming organs (B), and the cardiovascular system $(C)$ in the first level of the ATC classification (54\%). Additionally, all sets in the highcompetition market were oral forms, including tablets and capsules, and their price was less than 10,000 KRW.
These observations imply that low-priced chemical drugs used to treat chronic disease were more likely to be included in the high-competition market.

\section{A regression analysis}

Table 2 presents a multivariate regression for the price variance in the 986 sets. Note that price variance was calculated by the difference between the maximum price and minimum price divided by the maximum price in the sets. Thus, increased price variance indicates price competition in the set. Two models, including the simple model and the expanded model, are presented in Table 2.

The route of administration and the approval year of the originator were significantly associated with price competition in the simple model. More specifically, drugs in injection and other forms were less likely to experience price competition than drugs in oral forms. In a similar vein, drugs approved recently were less likely to experience price competition. However, the type of originator (chemicals or biologics) was not significantly related to price competition.

In the expanded model, we observed consistent results for the variables on the route of administration and approval year. However, the type of originator was significantly related to price competition in the expanded 
Table 2 Adjusted association between generic competition and drug prices

\begin{tabular}{|c|c|c|c|c|c|c|}
\hline \multirow[t]{2}{*}{ Variables } & \multicolumn{3}{|c|}{ The Simple Model } & \multicolumn{3}{|c|}{ The Expanded Model } \\
\hline & Estimates & Standard Error & $P$-value & Estimates & Standard Error & $P$-value \\
\hline \multicolumn{7}{|l|}{ ATC (reference J/L) } \\
\hline $2(A / B / C)$ & -0.0193 & 0.0131 & 0.1409 & 0.0017 & 0.0133 & 0.8974 \\
\hline $3(\mathrm{M} / \mathrm{N})$ & 0.0220 & 0.0149 & 0.1415 & 0.0395 & 0.0156 & 0.0114 \\
\hline 4 (Others) & -0.0498 & 0.0151 & 0.0010 & -0.0254 & 0.0150 & 0.0904 \\
\hline \multicolumn{7}{|c|}{ Route (reference Oral) } \\
\hline Injection & -0.0342 & 0.0117 & 0.0035 & -0.0309 & 0.0138 & 0.0255 \\
\hline Others & -0.0444 & 0.0133 & 0.0009 & -0.0337 & 0.0139 & 0.0153 \\
\hline Year & -0.0066 & 0.0007 & $<0.0001$ & -0.0045 & 0.0007 & $<0.0001$ \\
\hline \multicolumn{7}{|c|}{ Types (reference Chemicals) } \\
\hline Biologics & -0.0175 & 0.0186 & 0.3475 & -0.0457 & 0.0180 & 0.0114 \\
\hline \multicolumn{7}{|c|}{ Market (reference Duopoly) } \\
\hline $2(3-25)$ & & & & 0.0396 & 0.0080 & $<0.0001$ \\
\hline $3(26-75)$ & & & & 0.1473 & 0.0198 & $<0.0001$ \\
\hline $4(76-)$ & & & & 0.1650 & 0.0259 & $<0.0001$ \\
\hline \multicolumn{7}{|c|}{ New drug application (reference No) } \\
\hline Yes & & & & 0.0430 & 0.0141 & 0.0024 \\
\hline \multicolumn{7}{|c|}{ Manufacturers (reference Domestic) } \\
\hline Overseas & & & & 0.0087 & 0.0100 & 0.3836 \\
\hline \multicolumn{7}{|c|}{ Price (reference $<10^{3} \mathrm{KRW}$ ) } \\
\hline$\|\left(10^{3} \leq<10^{4}\right)$ & & & & 0.0418 & 0.0108 & 0.0001 \\
\hline III $\left(10^{4} \leq<10^{5}\right)$ & & & & 0.0422 & 0.0158 & 0.0076 \\
\hline IV $\left(10^{5} \leq<10^{6}\right)$ & & & & 0.0799 & 0.0271 & 0.0033 \\
\hline$V\left(10^{6} \leq\right)$ & & & & 0.1023 & 0.0371 & 0.0060 \\
\hline
\end{tabular}

model. Furthermore, market competitiveness and the price of the originator were significantly related to price variance. Drugs in the low-, medium-, and highcompetition markets were more likely to experience price competition than drugs in the duopoly market. Similarly, drugs in Levels II, III, and IV (high-cost drugs) were more likely to experience price competition than drugs in Level I (low-cost drugs). Finally, the designation of new drug applications (NDAs) was also significantly related to price competition.

\section{Discussion}

Governments and payers believe that there should be opportunities for cost savings in drug markets [14, 28, 29]. Based on this belief, governments have applied measures to introduce generic drugs in a timely manner, to stimulate price competition among generic drugs, and to increase generic penetration in various clinical settings. Meanwhile, several studies provide insights into competition, particularly the number of manufacturers, and its effect on lowering drug prices [11, 12, 26].

In the previous literature, the number of generic manufacturers for specific blockbuster markets in South
Korea has been reported, with conclusions that the South Korean market is extraordinary compared to the number of generic manufacturers in other high-income countries and rare price competition among a large number of generic manufacturers [16, 27]. We aimed to test the association between competition among manufacturers and drug prices in South Korea. To this end, a list of originator drugs approved by the national authority from 2000 to 2019 and their corresponding generic drugs were grouped along with the baseline information.

\section{Number of generic manufacturers in South Korea}

A total of 986 sets of originators and their corresponding generic drugs were identified in this study. Among them, 127 sets (13\%) include more than 25 generic manufacturers. Furthermore, 39 sets $(4 \%)$ include more than 75 generic manufacturers. These results are surprising when we directly compare the number of generic manufacturers in South Korea with the number in the United States. Li et al. (2018) categorized the topical dermatologic generic drug market in the United States into four groups [12]: 1-2, 3-4, 5-6, and more than 6 generic manufacturers. Similarly, Alpern et al. (2017) provide 
information on the number of oral antibiotic drug manufacturers in the United States [26]. In their study, the number of manufacturers for cefuroxime $250 \mathrm{mg}$ was 9 , and this number was the maximum among other oral antibiotic drugs. For the same drug, however, the number of manufacturers in South Korea is 38. This situation is even more surprising given that the pharmaceutical market in South Korea represents only $1.5 \%$ of the global market [30].

It is also noteworthy that 305 sets (31\%) are in the duopoly market. In this market, the mean and median of price variance were 0.0683 and 0.0130 , respectively, indicating that generics discounted by 6.83 and $1.30 \%$ are available. These figures, particularly the median $(0.0130)$ of price variance, imply scarce price competition in the duopoly market. Furthermore, a number of expensive drugs (10.5\%), which are above 100,000 KRW, belong to the duopoly market. Thus, policies to encourage marketing competition in duopoly markets should be formulated. In particular, off-patent drugs with few manufacturers should be prioritized areas to be addressed, and the MFDS's role in marketing authorizations for generics, including a timely review process for generic drug applications in the duopoly market, should be established.

\section{Association between competition and generic prices}

Given the characteristics of the South Korean market, we categorized the groups into four markets: duopoly, low-, medium-, and high-competition markets. In the descriptive analysis, we found that the majority of sets in duopoly markets present a small price variance, while a large number of sets in high-competitive markets present a large price variance. In the regression model, we found a positive association between price variance and the number of generic manufacturers, controlling for the ATC classification, route of administration, and type of originator drug. These observations are consistent with the experiences in other countries. It was well documented that market competition levels were associated with a price change in generic drugs in the United States. However, in interpreting these observations, the differences in health systems between the United States and South Korea should be noted.

The United States has a market-based health system. Approximately half of health care spending is publicly funded, but the beneficiaries of the funded program obtain health care services via private markets $[31,32]$. In the pharmaceutical sector, tighter pricing and reimbursement schemes do not exist, not even for generic drugs, and few generic manufacturers participate in the market [18]. On the other hand, the South Korean health system is financed by the National Health Insurance Services to cover the entire population [33]. In the pharmaceutical sector, there is a positive list system in which only drugs included in the formulary that demonstrate cost-effectiveness can be reimbursed [23]. Furthermore, tighter pricing and reimbursement schemes exist for generic drugs as well as new medicines, and a number of manufacturers participate in the market.

Given these differences, the United States is interested in a price increase for a certain drug. Specifically, price hikes have occurred for generic drugs on the market where an insufficient number of generic manufacturers exist. Thus, researchers are more interested in price increases in generics for which few manufacturers exist. On the other hand, many manufacturers produce generic drugs in South Korea. It is reasonable to anticipate fierce price competition among a large number of generic drugs. However, it has been reported that the increased number of generic manufacturers have not triggered price competition in reality $[16,23]$. Thus, we are interested in price variance among a large number of originator-generic sets.

This study demonstrates the association between the price of generics and market competitiveness in South Korea. However, in our observations, the association was not linear: the difference in the mean and median of price variance between the medium- and high competition markets was marginal $(0.0298$ and 0.0282 , respectively) in Table 1 . Furthermore, the estimates for the medium- and high competition markets were similar ( 0.1473 and 0.1650 , respectively) in Table 2 . These findings suggest that policies for managing the number of generic manufacturers fewer than 76 manufacturers could be introduced in the market without limiting price competition.

\section{Limitations}

This study includes the entire list of originator drugs approved by the national authority from 2000 to 2019 and their corresponding generic drugs. Thus, the study findings might be generalizable to all types of drugs in the South Korean market. However, our study has limitations. While we attempted to capture all drugs approved from 2000 to 2019, information on their sales was not included. In a similar vein, this study used price variance, calculated as the difference between the maximum price and minimum price in the sets divided by the maximum price, to measure price competition. However, the market share of the minimum priced generic drug might be marginal, implying that the effect of price competition might have less implications in managing pharmaceutical expenditure.

\section{Conclusions}

The positive association between price variance and market competitiveness is still consistent in South 
Korea, where rare price competition among a large number of generic manufacturers has been reported. However, no significant price variance between medium- and high-competition markets was observed. These findings suggest that policies for managing the number of generic manufacturers fewer than 76 manufacturers could be introduced in the market without limiting price competition. Furthermore, it should be noted that the majority of drugs are in a duopoly market without price competition in South Korea. Thus, policies to encourage marketing competition and to address rare price competition issues should be formulated for the duopoly market. In particular, off-patent drugs with few manufacturers should be prioritized areas to be addressed, and the MFDS's role in timely marketing authorizations for generics should be established.

\section{Abbreviations}

ATC: Anatomical Therapeutic Chemical; HIRA: Health Insurance Review and Assessment Services; KPIS: Korea Pharmaceutical Information Service; MFDS: Ministry of Food and Drug Safety; NDA: New drug applications; NHIS: National Health Insurance Services

\section{Acknowledgements}

Not applicable.

\section{Author's contributions}

KS designed the study, collected and analyzed data, and wrote the first draft. The author read and approved the final manuscript.

\section{Funding}

This work was supported by the Ministry of Education of the Republic of Korea and the National Research Foundation of Korea (NRF2019S1A5A8032445)

\section{Availability of data and materials}

We used publicly available data, provided by the Health Insurance Review and Assessment Services and the Ministry of Food and Drug Safety.

\section{Ethics approval and consent to participate}

Not applicable.

\section{Consent for publication}

Not applicable.

\section{Competing interests}

Not applicable.

Received: 16 February 2020 Accepted: 10 September 2020

Published online: 15 September 2020

\section{References}

1. Dalen DM, Strom S, Haabeth T. Price regulation and generic competition in the pharmaceutical market. Eur J Health Econ. 2006;7(3):208-14.

2. Wheaton JJ. Generic competition and pharmaceutical innovation: the drug Price competition and patent term restoration act of 1984. Cath UL Rev. 1985:35:433.

3. Engelberg AB, Kesselheim AS, Avorn J. Balancing innovation, access, and profits-market exclusivity for biologics. N Engl J Med. 2009;361(20):1917-9.

4. Son K-B. Establishing healthy pharmaceutical regulations on statutory exclusivity: lessons from the experience in the European Union, Canada, South Korea, Australia, and the United States. J Generic Med. 2018;14(4): 167-74.

5. Kesselheim AS, Misono AS, Lee JL, Stedman MR, Brookhart MA, Choudhry NK, et al. Clinical equivalence of generic and brand-name drugs used in cardiovascular disease: a systematic review and meta-analysis. JAMA. 2008; 300(21):2514-26.

6. Gassman AL, Nguyen $C P$, Joffe HV. FDA regulation of prescription drugs. $N$ Engl J Med. 2017:376(7):674-82.

7. Kesselheim AS, Stedman MR, Bubrick EJ, Gagne JJ, Misono AS, Lee JL, et al. Seizure outcomes following the use of generic versus brand-name antiepileptic drugs. Drugs. 2010;70(5):605-21.

8. Costa-Font J, McGuire A, Varol N. Price regulation and relative delays in generic drug adoption. J Health Econ. 2014;38:1-9.

9. Lexchin J. The effect of generic competition on the price of brand-name drugs. Health Policy (Amsterdam, Netherlands). 2004;68(1):47-54.

10. Garattini L, Padula A. Competition in pharmaceuticals: more product- than price-oriented? Eur J Health Econ. 2018;19(1):1-4.

11. Barbieri JS, Margolis DJ, Brod BA. Influence of market competition on tetracycline pricing and impact of Price increases on clinician prescribing behavior. J Invest Dermatol. 2017;137(12):2491-6.

12. Li DG, Joyce C, Mostaghimi A. Association between market competition and prices of generic topical dermatology drugs. JAMA Dermatol. 2018;154(12): 1441-6.

13. Vogler S. How large are the differences between originator and generic prices? Analysis of five molecules in 16 European countries. Farmeconomia Health Econ Ther Pathw. 2012;13(3S):29-41.

14. Wouters OJ, Kanavos PG, Mc KM. Comparing generic drug Markets in Europe and the United States: prices, volumes, and spending. Milbank Q. 2017;95(3):554-601.

15. Kesselheim AS, Avorn J, Sarpatwari A. The high cost of prescription drugs in the United States: origins and prospects for reform. JAMA. 2016;316(8):858-71.

16. Son K-B. Generic atorvastatin and rosuvastatin in the south Korean market: time of introduction in relation to manufacturer characteristics. Expert Rev Pharmacoecon Outcomes Res. 2019:1-8.

17. Sarpatwari A, DiBello J, Zakarian M, Najafzadeh M, Kesselheim AS. Competition and price among brand-name drugs in the same class: a systematic review of the evidence. PLoS Med. 2019;16(7):e1002872.

18. Belloni A, Morgan D, Paris V. Pharmaceutical expenditure and policies; 2016.

19. Cohen E, Hall M, Lopert R, Bruen B, Chamberlain LJ, Bardach N, et al. Highexpenditure pharmaceutical use among children in Medicaid. Pediatrics. 2017;140(3):e20171095.

20. Joyce G, Henkhaus LE, Gascue L, Zissimopoulos J. Generic drug Price hikes and out-of-pocket spending for Medicare beneficiaries. Health Affairs (Project Hope). 2018;37(10):1578-86.

21. Leukemia ECM. The price of drugs for chronic myeloid leukemia (CML) is a reflection of the unsustainable prices of cancer drugs: from the perspective of a large group of CML experts. Blood J Am Soc Hematol. 2013;121(22): 4439-42.

22. Drummond MF, Schwartz JS, Jönsson B, Luce BR, Neumann PJ, Siebert U, et al. Key principles for the improved conduct of health technology assessments for resource allocation decisions. Int J Technol Assess Health Care. 2008;24(3):244-58.

23. Son K-B. Understanding the adoption of new drugs decided by several stakeholders in the south Korean market: a nonparametric event history analysis. Heal Econ Rev. 2018;8(1):31.

24. Ferrario A, Dedet G, Humbert T, Vogler S, Suleman F, Pedersen HB. Strategies to achieve fairer prices for generic and biosimilar medicines. BMJ. 2020;368,

25. Alpern JD, Song J, Stauffer WM. Essential medicines in the United States why access is diminishing. N Engl J Med. 2016;374(20):1904-7.

26. Alpern JD, Zhang L, Stauffer WM, Kesselheim AS. Trends in pricing and generic competition within the Oral antibiotic drug market in the United States. Clin Infect Dis. 2017;65(11):1848-52.

27. Son K-B, Bae S. Patterns of statin utilisation for new users and market dynamics in South Korea: a 13-year retrospective cohort study. BMJ Open. 2019:9(3):e026603.

28. Vogler S, Paris V, Ferrario A, Wirtz VJ, de Joncheere K, Schneider P, et al. How can pricing and reimbursement policies improve affordable access to medicines? Lessons learned from European countries. Appl Health Econ Health Policy. 2017;15(3):307-21.

29. Vogler S, Zimmermann N, de Joncheere K. Policy interventions related to medicines: Survey of measures taken in European countries during 20102015. Health policy (Amsterdam, Netherlands). 2016;120(12):1363-77.

30. Korea Health Industry Development Institute. Pharmaceutical industry analysis report. Chungbuk: Korea Health Industry Development Institute; 2017. 
31. Papanicolas I, Woskie LR, Jha AK. Health care spending in the United States and other high-income countries. JAMA. 2018;319(10):1024-39.

32. Mossialos E, Wenzl M, Osborn R, Sarnak D. 2015 international profiles of health care systems: Canadian Agency for Drugs and Technologies in health; 2016

33. World Health Organization. Regional Office for the Western P. Republic of Korea health system review. Manila: WHO Regional Office for the Western Pacific; 2015.

\section{Publisher's Note}

Springer Nature remains neutral with regard to jurisdictional claims in published maps and institutional affiliations.

- fast, convenient online submission

- thorough peer review by experienced researchers in your field

- rapid publication on acceptance

- support for research data, including large and complex data types

- gold Open Access which fosters wider collaboration and increased citations

- maximum visibility for your research: over $100 \mathrm{M}$ website views per year

At $\mathrm{BMC}$, research is always in progress. 